\title{
Probabilistic Load Flow Solution Considering Optimal Allocation of SVC in Radial Distribution System
}

\author{
Walaa Ahmed $^{1}$, Ali Selim ${ }^{1,2}$, Salah Kamel ${ }^{1,3}$, Juan $\mathrm{Yu}^{3}$, Francisco Jurado ${ }^{2 *}$ \\ ${ }^{1}$ Department of Electrical Engineering, Faculty of Engineering, Aswan University, 81542 Aswan (Egypt) \\ ${ }^{2}$ Department of Electrical Engineering, University of Jaén, 23700 EPS Linares, Jaén (Spain) \\ ${ }^{3}$ State Key Laboratory of Power Transmission Equipment and System Security and New Technology, \\ Chongqing University, Chongqing 400030 (China)
}

Received 26 July 2018 | Accepted 24 October 2018 | Published 5 November 2018

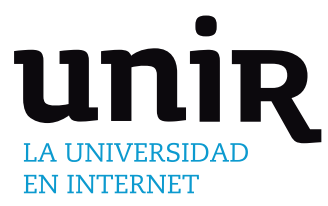

KEYWORDS

Probabilistic Load Flow, SVC, Radial Distribution Systems, Multi-objective Particle Swarm Optimization.

DOI: $10.9781 /$ ijimai.2018.11.001

\section{INTRODUCTION}

$\mathrm{R}$ ADIAL structure of distribution systems along with the high ratio of current to voltage levels lead to an increase in the power loss and voltage deviation of distribution systems [1]. Therefore, real power loss and voltage deviation are considered one of the crucial problems in the restructured power system. Reactive power compensation devices would allow Static Var Compensator be the effective method to overcome these technical issues, whereby injecting a sufficient reactive power in suitable distribution system points which help in improving the voltage profile and decreasing the power loss.

Various VAR compensator types are utilized to enhance the steadystate transmittable power and control the voltage profile along the transmission line [2]. Capacitor banks, voltage regulators, Dynamic Voltage Restorer (DVR) and Distributed Flexible AC Transmission System devices (D-FACTS), are examples of such compensators. Recently, a reactive power compensation using the PV inverter is used in distribution systems to relax the voltage regulator [3]. However, D-FACTS devices are considered the best way to enhance voltage profile in power systems by increasing the capacity of the transmission line and controlling power flow in a flexible and fast way $[4,5]$. There are different kinds of these devices such as the series compensator, shunt compensator, combined series-series compensator, and combined series-shunt compensator [6]. The Static Var Compensator (SVC) is considered a shunt FACTS device compensator. It has the ability to control the line power flow by injecting convenient reactive power into the system.

Decreasing the power losses can be achieved with integrated renewable energy resources. Recently, different methods have been

\footnotetext{
* Corresponding author.

E-mail address: fjurado@ujaen.es
}

presented using neural networks and machine learning to decrease the power and energy losses in the distribution system in existence of photovoltaic (PV) [7, 8]. In addtion, some methods have been presented to determine the power loss in smart grids $[9,10]$. A steady-state security region-based chance-constrained model has been established to solve the power injection uncertainties of renewable energy resources [11].

Proper location and size of SVC decrease power losses and reduce Voltage Deviation (VD) to enhance the voltage profile. Many studies have addressed the optimal size and location of the SVC. Two different optimization methodologies have been investigated to solve the optimization problem, the first methodology tried to solve the optimization problem with a single objective function such as minimizing the total power loss while the second dealt with multiobjective function. However, both the total power loss and voltage deviation can be simultaneously minimized in distribution systems using Multi-Objective Optimization Problems (MOOP). A Pareto dominance concept can be used to classify the solutions of the MOOP as dominated or non-dominated solutions. An optimal location and setting of SVC using non-dominated sorting particle swarm optimization are introduced in [12]. Improvement by voltage profile using SVC in a distribution substation is presented in [13]

Many algorithms have been applied to solve MOOP such as; Pareto Archived Evolution Strategy (PAES) [14], Nondominated Sorting Genetic Algorithm (NSGA-II) [15], Strength Pareto Evolutionary Algorithm(SPEA) and improved version SPEA2 [16], Multi-objective Particle Swarm Optimization (MOPSO) [17], Pareto Envelope-based Selection Algorithm II (PESA-II)[18].

Nevertheless, all papers in the survey have solved the optimal SVC placement problem as a deterministic case neglecting load fluctuation [19]. The electric load can be affected by time and weather condition, however, there are random factors components depending on the consumers that cannot be modeled [20]. So, the deterministic load 
flow method does not satisfactory analyze the performance and the impact of SVC in the distribution system under load uncertainty. As a consequence, the method treats with specific values neglecting any uncertainties in the system, this can be done by using the Probabilistic Load Flow (PLF) [21]. PLF is presented in [22, 23] and further developed in $[24,25]$. PLF can be solved by an analytical technique or Monte Carlo method [26]. Monte Carlo is a more accurate method, however, the analytical technique can give an acceptable solution with less computational cost compared to the Monte Carlo method [27]. There are different analytical methods to solve the PLF problem, like cumulants method [28, 29], or point estimate method [30]. These methods utilized the convolution properties to present the input and the output values of the systems as random variables [31, 32]. Moreover, the main feature of these methods is their computational efficiency in treating with random variables. A study of PLF by using a combined Cumulants and the Gram-Charlier expansion is presented in [31].

In this paper, a multi-objective function and probabilistic load flow are used to study the performance of including optimal SVC in the radial distribution system. Therefore, the topic discussed, and contribution of the work could be summarized as follows:

- Developing probabilistic load flow algorithm considering the optimal allocation of Static Var Compensator (SVC) in radial distribution systems;

- Pareto Envelope-based Selection Algorithm II (PESA-II) is used as a multi-objective optimization method to find the optimal location and size of SVC;

- Fuzzy logic decision maker is developed, and incorporated into PESA-II to find the best solution from the Pareto optimal set;

- Power loss and voltage deviation are used as multi-objective functions to be minimized.

- Combined cumulants and gram-chalier expansion are used for solving the probabilistic load flow problem;

- The developed algorithm is validated using 33- bus and 69-bus distribution systems;

- The number of iterations and computation time required for solving the probabilistic load flow problem are reduced compared with the Monte Carlo method.

The paper is organized as follows: Section II introduces the mathematical model of the probabilistic load flow. Section III describes the optimization process using PESA-II. Section IV gives the numerical results. Finally, the conclusions are presented in Section V.

\section{Probabilistic Load Flow Analysis}

The load flow is represented by a system of non-linear equations that reflect the balance at steady state in the network between the power consumed and the power produced, Generally speaking, probabilistic load flow calculations consist of two parts linearization of load flow equations and convolution calculations. The cumulant method is used to perform convolution computation of random variables and the Gram-Charlier series expansion, to compute their distributions.

$$
\begin{aligned}
& P_{i}=V_{i} \sum_{k=1}^{n} V_{k}\left(G_{i k} \cos \theta_{i k}+B_{i k} \sin \theta_{i k}\right) \\
& Q_{i}=V_{i} \sum_{k=1}^{n} V_{k}\left(G_{i k} \sin \theta_{i k}-B_{i k} \cos \theta_{i k}\right)
\end{aligned}
$$

The active and reactive power $P, Q$ at bus $i$ are calculated using the voltage $V_{i}$ and the values of the conductance $G_{i k}$, susceptance $B_{i k}$, and the angle $\theta_{i k}$ between the bus $i$ and the connected bus $k$ for all $n$ buses of the system.

\section{A. Linear Approximation}

The linearization of load flow equations is performed around the solution obtained with a deterministic load flow, based on the expected values of the system. These expected values are obtained after solving the problem of the deterministic method of the Newton-Raphson load flow calculation. To illustrate this technique, two random variables $X$ and $Y$ are considered. At some point in the problem, these random variables are multiplied to give a third random variable $Z$.

$$
Z=X . Y
$$

If the deviations of $X$ and $Y$ are represented around their mean values $\bar{X}$ and $\bar{Y}$ by $\Delta X$ and $\Delta Y$, respectively, the following can be assumed.

$$
X \cong \bar{X}+\Delta X . \text { and } Y \cong \bar{Y}+\Delta Y
$$

It is obtained, after neglecting the terms of the second order $\Delta X \quad \Delta Y$

$$
Z \cong \overline{X Y}+\bar{X} \Delta Y+\bar{Y} \Delta X=\bar{X} Y+\bar{Y} X+\overline{X Y}
$$

Therefore, if changes of random variables are small, the variable $Z$ can be linearized since the expected values for $X$ and $Y$ are known. This technique can be applied to the angles and voltages in (6) of the load flow. Thus, the

$$
\begin{aligned}
& P_{i}=V_{i} \sum_{k=1}^{n}\left(e_{i n}^{\prime}+f_{i n}^{\prime} \delta_{i}-f_{i n}^{\prime} \delta_{n}+g_{i n}^{\prime} V_{i}+h_{i n}^{\prime} V_{n}\right) \\
& q_{i}=V_{i} \sum_{k=1}^{n}\left(e_{i n}^{\prime \prime}+f_{i n}^{\prime \prime} \delta_{i}-f_{i n}^{\prime \prime} \delta_{n}+g_{i n}^{\prime \prime} V_{i}+h_{i n}^{\prime \prime} V_{n}\right)
\end{aligned}
$$

Where $e^{\prime}, f^{\prime}, g^{\prime}, h^{\prime}, e^{\prime \prime}, f^{\prime \prime}, g^{\prime \prime}$ and $h^{\prime \prime}$ are calculated from system parameters and expected values for the variables.

\section{B. Convolution Calculation}

Suppose that there are two independent random variables $\mathrm{X}$ and $\mathrm{Y}$, and their probability density functions $f_{1}(x)$ and $f_{2}(y)$, respectively, then $Z=X+Y$ is still a random variable. The probability density function of $Z$ is:

$$
\phi(Z)=\int_{-\infty}^{\infty} f(x, z-x) d x=\int_{-\infty}^{\infty} f_{1}(x) f_{2}(z-x) d x
$$

Its distribution function is

$$
F(Z)=\int_{-\infty}^{z} \int_{-\infty}^{\infty} f_{1}(x) f_{2}(z-x) d x d z
$$

\section{Moments and Cumulants}

The convolution random variables can be replaced by the sum of their cumulants. The cumulants and moments of a random variable are the set of constants that reveal the properties of $\mathrm{X}$ and determine its distribution function [27]. However, cumulants have a number of properties that make their manipulation more useful. The cumulant method has low computational cost $[28,30]$. It is also a flexible method that uses any random variable and not just normal distributions. Most statistical calculations using cumulants method are simpler than the corresponding calculation using moments.

When a random variable distribution is known, its moment of every order can then be obtained. Suppose the density function of a continuous random variable $\mathrm{x}$ is $\mathrm{g}(\mathrm{x})$, then its $v$-order moment $\alpha_{v}$ can be calculated by the following equation:

$$
\alpha_{v}=\int_{-\infty}^{\infty} x^{v} \mathrm{~g}(x) d x
$$

When $v=1$, the expectation of the random variable $x$,

$$
\mu=\alpha_{1}=\int_{-\infty}^{\infty} x \mathrm{~g}(x) d x
$$

From the expectation $\mu$, the central moment of every order $M_{v}$ 
can be calculated. Then the central moment of every order $M_{v}$ can be solved by the expectation,

$$
M_{v}=\int_{-\infty}^{\infty}(x-\mu)^{v} \mathrm{~g}(x) d x
$$

The relationships between the cumulants and the moments of every order are given in $[28,30]$.

\section{Gram-Charlier Expansion}

The Gram-Charlier series expansion is mainly used in probabilistic production simulation [28]. These series represent the random variable distribution function by using the derivatives of the random variable. The coefficients of the series are formed by the random variable moments.

$$
\begin{aligned}
& F(x)=\Phi(x)+\frac{c_{1}}{1 !} \Phi^{\prime}(x)+\frac{c_{2}}{2 !} \Phi^{\prime \prime}(x)+\frac{c_{3}}{3 !} \Phi^{(3)}(x)+\cdots \\
& f(x)=\varphi(x)+\frac{c_{1}}{1 !} \varphi^{\prime}(x)+\frac{c_{2}}{2 !} \varphi^{\prime \prime}(x)+\frac{c_{3}}{3 !} \varphi^{(3)}(x)+\cdots
\end{aligned}
$$

Where $\Phi(x)$ and $\varphi(x)$ represent the cumulative distribution function (CDF) and probabilistic density function (PDF) of a normal distribution with $\mathrm{m}=0$ and and $\sigma=1 ; c_{v}$ are constant coefficients.

$$
c_{v}=(-1)^{v} \int_{-\infty}^{\infty} H_{v}(x) f(x) d x, v=1,2,3, \ldots
$$

Where $H_{v}(x)$ it is the Hermite polynomial of order $v$. In practice coefficients Gram-expansion Charlier $c_{v}$ can be expressed in terms of moments central random variable expansion object. The first seven coefficients are

$$
\begin{aligned}
& c_{0}=1, c_{1}=c_{2}=0, c_{3}=-\frac{\mu_{3}}{\sigma^{3}}, c_{4}=\frac{\mu_{4}}{\sigma^{4}}-3, c_{5}=-\frac{\mu_{5}}{\sigma^{5}}+10 \frac{\mu_{3}}{\sigma^{3}}, \\
& c_{6}=\frac{\mu_{6}}{\sigma^{6}}-15 \frac{\mu_{4}}{\sigma^{4}}+30, c_{7}=-\frac{\mu_{7}}{\sigma^{7}}-21 \frac{\mu_{5}}{\sigma^{5}}+105 \frac{\mu_{3}}{\sigma^{3}}
\end{aligned}
$$

\section{OPTIMIZATION Model}

This section presents the optimization methodologies which are used in this paper to determine the optimal size and location. The optimization model is based on PESA-II algorithm, two optimization approaches are presented in the following subsection:

\section{A. Objective Functions and Constraints}

The two objectives functions that should be minimized are $P_{\text {loss }}$ and Voltage Deviation (VD)

$$
F=\min \left(P_{\text {loss }}, V D\right)
$$

Where the power loss in each branch $z$ connected between two buses $i$ and $k$ is calculated as:

$$
P_{\text {loss_z }}=\mathrm{R}_{i k} \mathrm{I}_{z}{ }^{2}
$$

The total power losses for all branches $n \_b r$ in the distribution system can be expressed as follows:

$$
P_{\text {loss }}=\sum_{z=1}^{n \_b r} P_{\text {loss_z }}
$$

The voltage deviation at bus $i$ in terms of the specified voltage $V_{s e p}$ can be calculated as follow:

$$
V D_{i}=\left|\frac{V_{\text {sep }}-V_{i}}{V_{\text {sep }}}\right|
$$

and

$V D=\max \left(V D_{i}\right)$

\section{B. PESA-II Algorithm}

PESA-II algorithm can be concluded in the following steps [18]:

Step 1: Initialize number of population and two population-based parameters, the size of the Internal Population (IP) and the maximum size of the archive, or External Population (EP)

Step 2: Evaluate the objective functions for each individual $P_{i}$ chromosome in the population.

Step 3: Find the nondominated members and incorporate the nondominated members of IP into EP.

Step 4: If a termination criterion has been reached, then stop, returning the set of chromosomes in EP as the result. Otherwise, delete the current contents of IP, and repeat the following until $P_{i}$ new candidate solutions have been generated:

- With probability $P_{c}$, select two parents from EP, produce a single child via crossover, and mutate the child. With probability $\left(l-P_{c}\right)$, select one parent and mutate it to produce a child.

Step 5: increment the iteration number, endif iteration number is greater than max iter, otherwise go to step 2 .

\section{Fuzzy Decision-Making}

As shown in Fig. 1, a Pareto optimal set is determined using PESA-II, however, the main concern of the decision-maker is to find the best compromise solution from the Pareto set. A fuzzy decisionmaking approach is used in this paper to find the optimal Pareto point according to the decision-maker preferences. Fuzzy logic is considered a range decision in which the output is obtained by fuzzification of inputs and outputs, from the associated membership functions (MFs). Hence, the value of the objective function $\mathrm{F}$ of individual $\mathrm{n}$ can be normalized as follows:

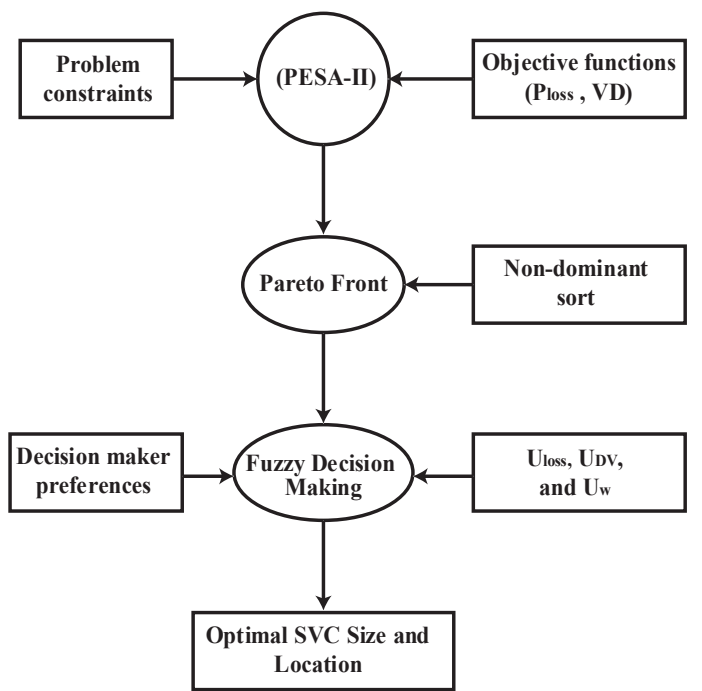

Fig.1. PESA-II with the fuzzy decision-making process. 


$$
u_{i}^{n}=\left\{\begin{array}{cc}
1 & F_{i} \leq F_{i}^{\text {min }} \\
\frac{F_{i}^{\text {max }}-F_{i}}{F_{i}^{\text {max }}-F_{i}^{\text {min }}} & F_{i}^{\text {max }} \leq F_{i} \leq F_{i}^{\text {min }} \\
0 & F_{i} \geq F_{i}^{\text {max }}
\end{array}\right.
$$

where, $F_{i}^{\text {min }}$ and $F_{i}^{\max }$ are the minimum and maximum value of the ith objective function among all non-dominated solutions respectively.

All normalized values are fuzzified using five triangular MFs for the two inputs power loss $U_{\text {loss }}$, voltage deviation $U_{V D}$, and the output weighting of the Pareto solution $U_{w}$, as shown in Fig. 2, the output $U_{w}$ , can be calculated using the rules as shown Fig. 3 and given in Table I. After applying the fuzzy decision making on the Pareto set, the output $\mathrm{U}_{\mathrm{w}}$ is a weighting factor between $[0 \sim 1]$ for each solution in the Pareto set according to the fuzzy rules, hence the best solution will be the one that has the maximum weighting value.

TABLE I. Rules OF THE Fuzzy CONTROLLER (VL =Very Low, L= Low, M= Medium, $\mathrm{H}=\mathrm{HIGH}$, ANd VH= VerY High)

\begin{tabular}{ccccccc}
\hline \hline & & \multicolumn{5}{c}{$\mathrm{U}_{\text {VD }}$} \\
\cline { 3 - 7 } & $\mathbf{V L}$ & VL & L & M & H & VH \\
\hline \multirow{4}{*}{ U $_{\text {Ploss }}$} & $\mathbf{L}$ & VL & L & L & VL & VL \\
& $\mathbf{M}$ & VL & L & M & M & L \\
& H & VL & L & M & H & H \\
& VH & VL & L & M & H & VH \\
\hline
\end{tabular}

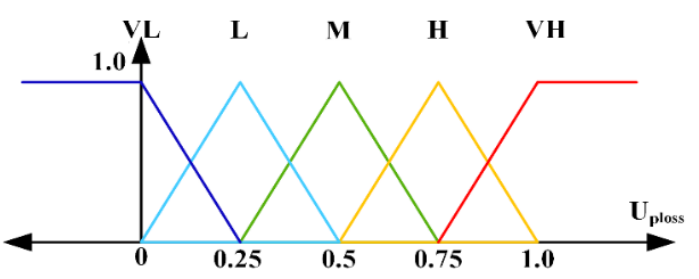

a. Normalized power loss membership plot.

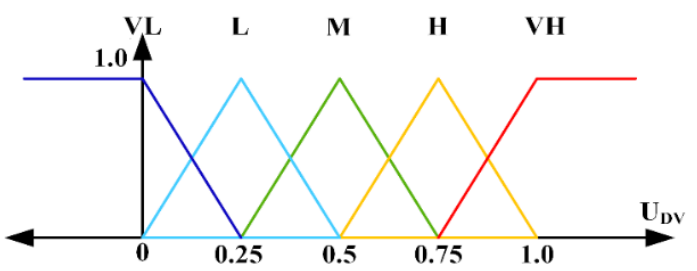

b. Normalized voltage deviation memberships plot.

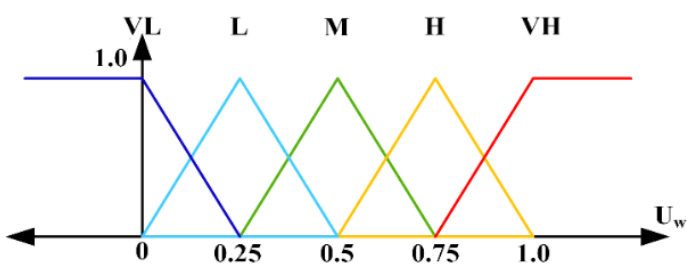

c. Normalized weighting membership plot.

Fig. 2. Fuzzy membership plot for normalized objective functions values.

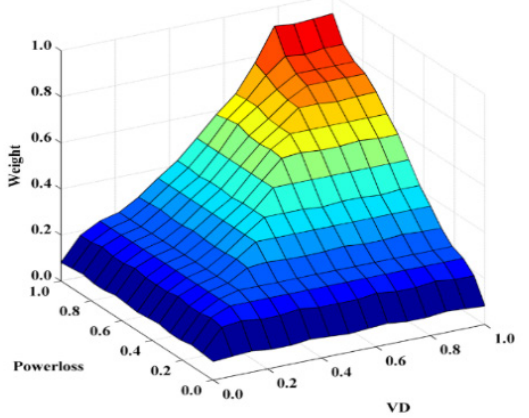

Fig. 3. Fuzzy rules.

\section{RESULTS}

In this section, the obtained results of two standard test systems are presented and comprehensively discussed.

\section{A. 33-Bus Radial System}

The proposed approach is tested on the 33-bus radial distribution system. The single line diagram is displayed in Fig. 4. Statistical data of loads at all PQ buses are given in [33] and modeled as normal variables. The results of mean and standard deviation of voltages at PQ buss in the system without including SVC are given in Table II. The results in Table II show that the voltage obtained by the analytical technique is virtually identical to the results obtained with MCS. Also, it can be seen in Fig. 5 that CDFs for analytical technique and MCS at bus 18 and bus 33 are virtually identical.

There are two cases of connected SVC based on the SVC numbers: case 1 for one SVC and case 2 for two SVC. The optimal size and location for the two cases obtained by different multi-objective optimization algorithms are summarized in Table III and Table IV. It is obvious from the two tables that PESA-II gives the better solution for the optimal size and location for SVC compared to the other optimization algorithms.

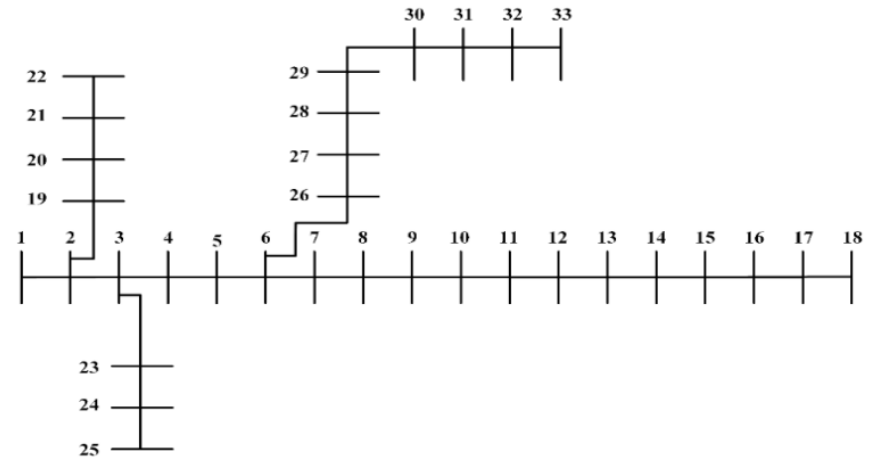

Fig.4. 33 bus single line diagram. 
TABLE II.

Voltages in 33-Bus Distribution System Without IncLuding SVC

\begin{tabular}{|c|c|c|c|c|}
\hline \multirow[t]{2}{*}{ Bus } & \multicolumn{2}{|c|}{ Analytical technique } & \multicolumn{2}{|c|}{ Monte Carlo } \\
\hline & $\mu$ & $\sigma$ & $\mu$ & $\Sigma$ \\
\hline 2 & 0.997031 & $3.74 \mathrm{E}-05$ & 0.997027 & 0.000038 \\
\hline 3 & 0.982922 & 0.000232 & 0.982894 & 0.000236 \\
\hline 4 & 0.975425 & 0.000318 & 0.975381 & 0.000326 \\
\hline 5 & 0.968013 & 0.000416 & 0.967953 & 0.000426 \\
\hline 6 & 0.949573 & 0.00068 & 0.949471 & 0.000698 \\
\hline 7 & 0.946056 & 0.00071 & 0.945945 & 0.000729 \\
\hline 8 & 0.932426 & 0.000886 & 0.932283 & 0.000906 \\
\hline 9 & 0.926108 & 0.000985 & 0.92595 & 0.001006 \\
\hline 10 & 0.920248 & 0.001089 & 0.920074 & 0.001111 \\
\hline 11 & 0.919381 & 0.001105 & 0.919205 & 0.001129 \\
\hline 12 & 0.91787 & 0.001136 & 0.91769 & 0.001160 \\
\hline 13 & 0.91171 & 0.001265 & 0.911515 & 0.001290 \\
\hline 14 & 0.909425 & 0.001318 & 0.909225 & 0.001344 \\
\hline 15 & 0.908002 & 0.001342 & 0.907799 & 0.001368 \\
\hline 16 & 0.906624 & 0.001371 & 0.906416 & 0.001396 \\
\hline 17 & 0.904581 & 0.001402 & 0.904368 & 0.001429 \\
\hline 18 & 0.903969 & 0.001413 & 0.903754 & 0.001440 \\
\hline 19 & 0.996503 & $4.28 \mathrm{E}-05$ & 0.996498 & 0.000043 \\
\hline 20 & 0.992926 & 0.000145 & 0.992921 & 0.000143 \\
\hline 21 & 0.992221 & 0.000173 & 0.992217 & 0.000172 \\
\hline 22 & 0.991584 & 0.000211 & 0.991579 & 0.000210 \\
\hline 23 & 0.979338 & 0.000326 & 0.979309 & 0.000331 \\
\hline 24 & 0.972671 & 0.000547 & 0.972639 & 0.000553 \\
\hline 25 & 0.969348 & 0.000655 & 0.969315 & 0.000664 \\
\hline 26 & 0.947647 & 0.000715 & 0.94754 & 0.000734 \\
\hline 27 & 0.945087 & 0.000765 & 0.944975 & 0.000786 \\
\hline 28 & 0.933669 & 0.00102 & 0.93353 & 0.001048 \\
\hline 29 & 0.925466 & 0.001218 & 0.925307 & 0.001251 \\
\hline 30 & 0.921915 & 0.001304 & 0.921747 & 0.001339 \\
\hline 31 & 0.917762 & 0.001366 & 0.917585 & 0.001403 \\
\hline 32 & 0.916849 & 0.001381 & 0.916669 & 0.001418 \\
\hline \multirow[t]{2}{*}{33} & 0.916566 & 0.001383 & 0.916385 & 0.001421 \\
\hline & \multicolumn{2}{|c|}{ Base $M V A=100$} & \multicolumn{2}{|c|}{ Base $K V=12.66$} \\
\hline
\end{tabular}

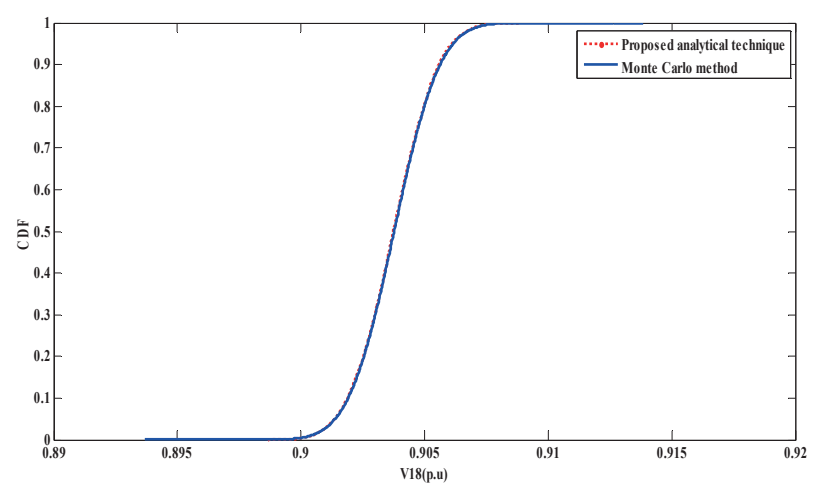

a. CDF of the voltage at bus 18 .

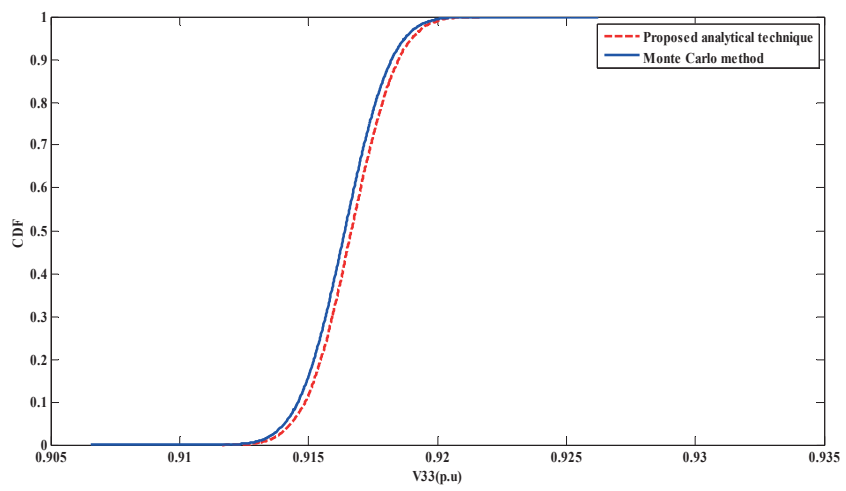

b. CDF of the voltage at bus 33 .

Fig. 5. CDF of the voltage at bus 18 and bus 33 without SVC.

TABLE III. Optimal Size and Location of Single SVC Using Different OPTIMIZATION AlgORITHMS FOR 33 Bus SySTEM

\begin{tabular}{ccccc}
\hline Method & $\begin{array}{c}\text { SVC } \\
\text { Location }\end{array}$ & $\begin{array}{c}\text { SVC Size } \\
(\mathrm{kVAR})\end{array}$ & $\begin{array}{c}\text { Power losses } \\
(\mathrm{kW})\end{array}$ & VD (p.u) \\
\hline MOPSO & 7 & 2137.70 & 158.77 & 0.0632 \\
NSGA II & 7 & 2146.46 & 158.89 & 0.0631 \\
PESA-II & 7 & 1896.35 & $\mathbf{1 5 6 . 3 8}$ & $\mathbf{0 . 0 6 5 3}$ \\
SPEA2 & 7 & 2400.69 & 163.38 & 0.0608 \\
\hline \hline
\end{tabular}

TABLE IV. Optimal Size And Location of Two SVC Using Different Optimization Algorithms For 33 Bus System

\begin{tabular}{ccccc}
\hline Method & $\begin{array}{c}\text { SVC } \\
\text { Location }\end{array}$ & $\begin{array}{c}\text { SVC Size } \\
(\mathrm{kVAR})\end{array}$ & $\begin{array}{c}\text { Power losses } \\
(\mathrm{kW})\end{array}$ & $\begin{array}{c}\text { VD } \\
(\mathrm{p} . \mathrm{u})\end{array}$ \\
\hline \multirow{2}{*}{ MOPSO } & 14 & 1071.60 & 194.14 & 0.0307 \\
& 30 & 1847.60 & & \\
\multirow{2}{*}{ NSGA II } & 14 & 1041.57 & 191.77 & 0.0308 \\
& 30 & 1851.95 & & \\
PESA-II & 13 & 1225.18 & $\mathbf{1 8 4 . 5 7}$ & $\mathbf{0 . 0 3 6 7}$ \\
& 30 & 1509.74 & & \\
\multirow{2}{*}{ SPEA2 } & 14 & 1053.00 & 192.97 & 0.0307 \\
\hline
\end{tabular}

Fig. 6 shows the voltage profile of 33 bus with SVC control device in the mentioned two cases. Fig. 7 and Fig. 8 gives the Pareto Optimal Front for 33-bus for single SVC and two SVCs respectively. Fig. 9 gives PDF and CDF of voltages at bus 18 with and without SVC. Fig. 10 shows PDF and CDF of voltages at bus 33. Expected voltage profile of 33 bus system with single SVC in 24 hours is shown in Fig. 11, however Fig. 12 gives the SD of it in 24 hours. Expected voltage profile of 33 bus system with two SVC in 24 hours is shown in Fig. 13, however, Fig. 14 gives the SD of it in 24 hours. Table V gives a comparison between expected SD values with/without SVC, the expected value of Vmin and Vmax are improved in both cases. Also, Qlosses is decreased in case 1 and case 2 compared to the base case, however, the standard deviation is not improved in the two cases compared to without SVC. Computational times of two cases are presented in Table VI. 


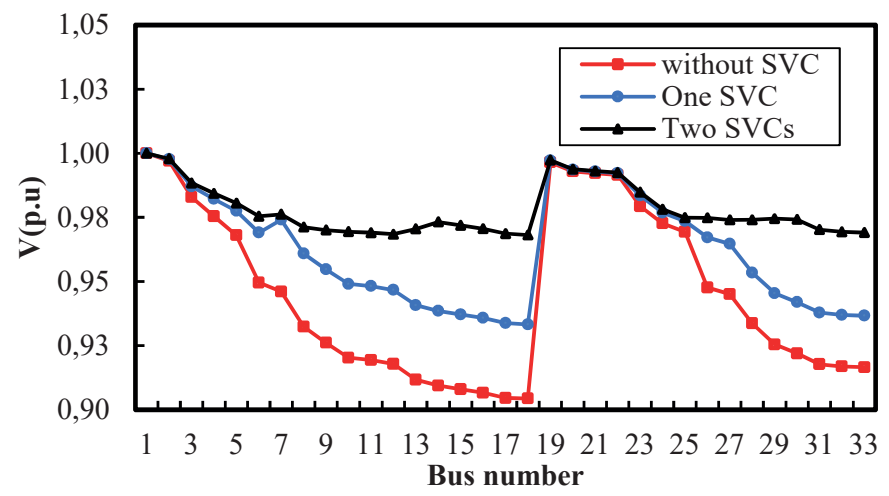

Fig. 6. Voltage profile of 33 bus with control device in different cases.

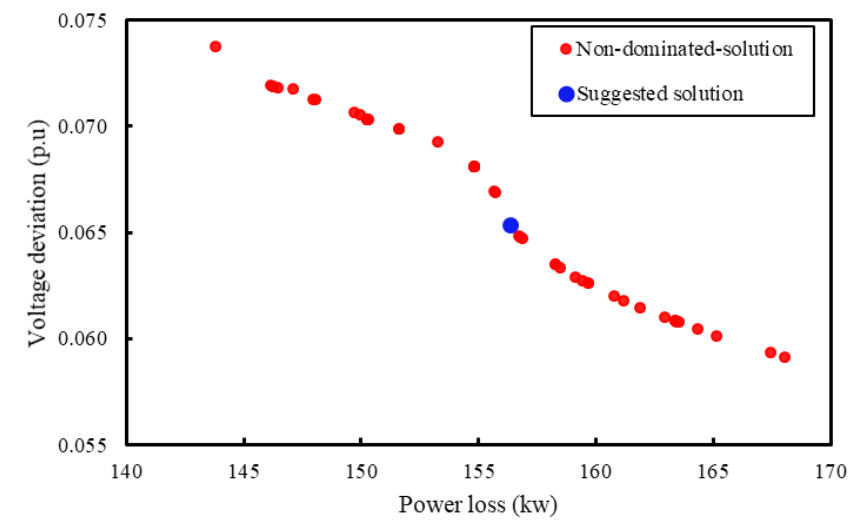

Fig. 7. Pareto Optimal Front for 33 bus with single SVC.

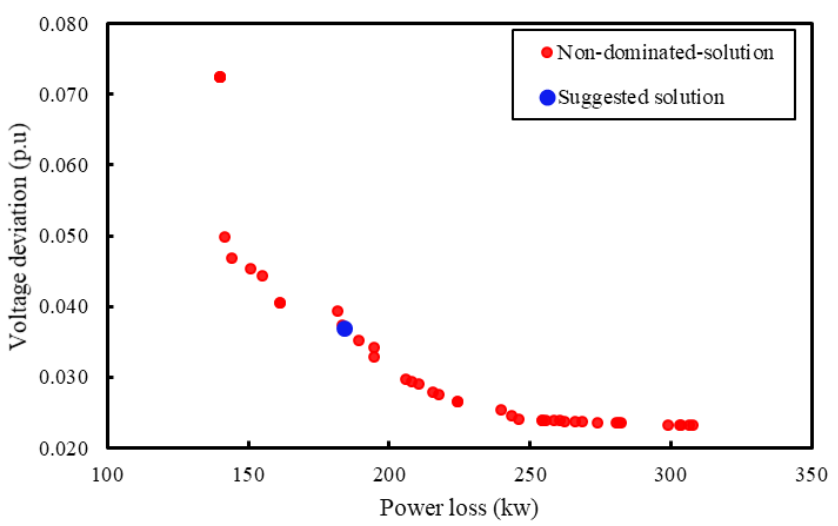

Fig. 8. Pareto Optimal Front for 33 bus with two SVC.

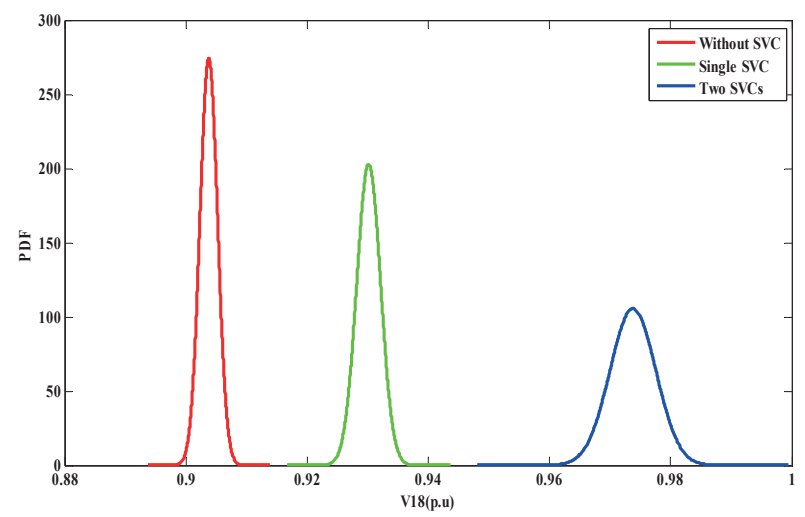

a. PDF

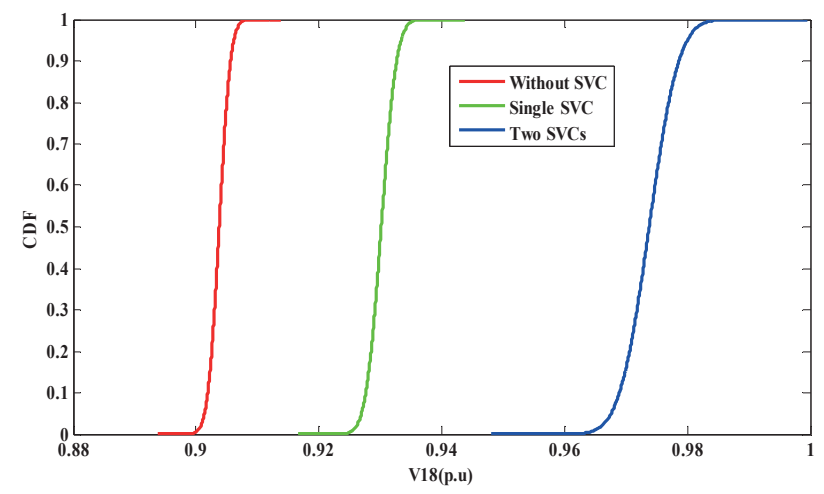

b. $\mathrm{CDF}$

Fig. 9. PDF and CDF of bus 18 .

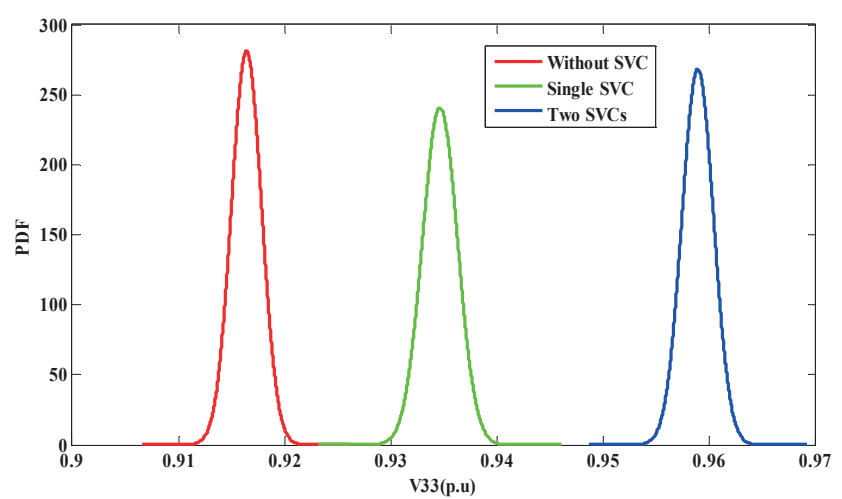

a. PDF

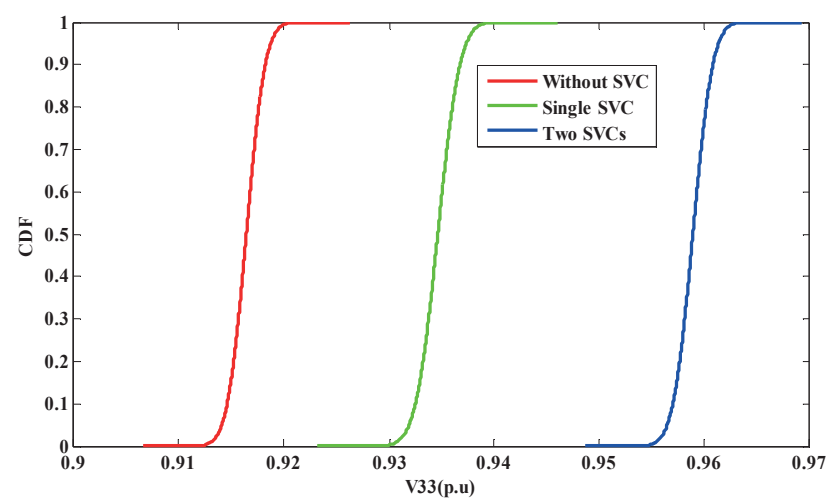

b. $\mathrm{CDF}$

Fig.10. PDF and CDF of 33 bus.

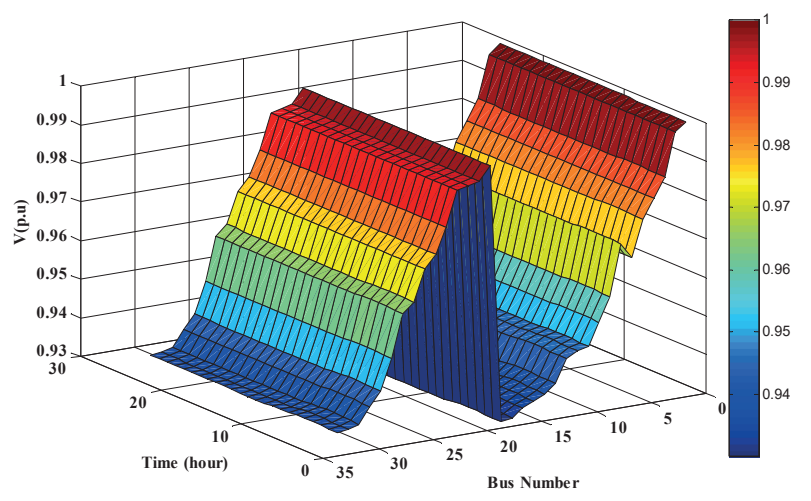

Fig. 11. Expected voltage profile of 33 bus system with single SVC. 


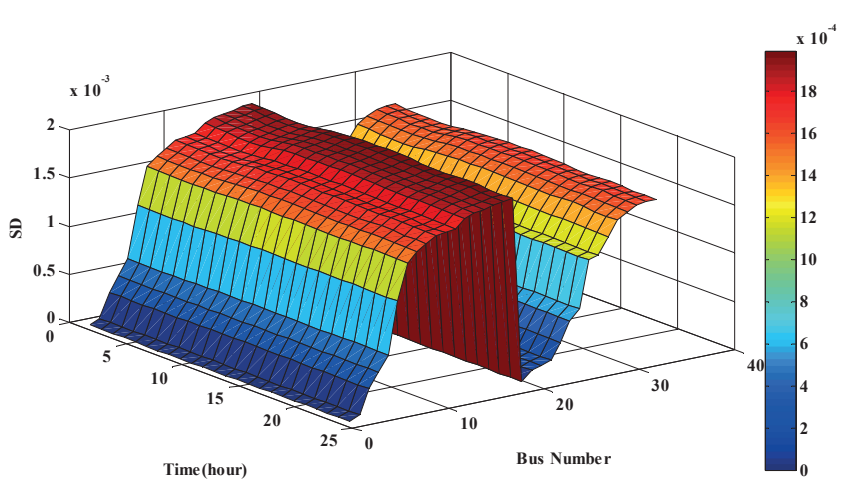

Fig. 12. Standard Deviation of 33 bus system with single SVC.

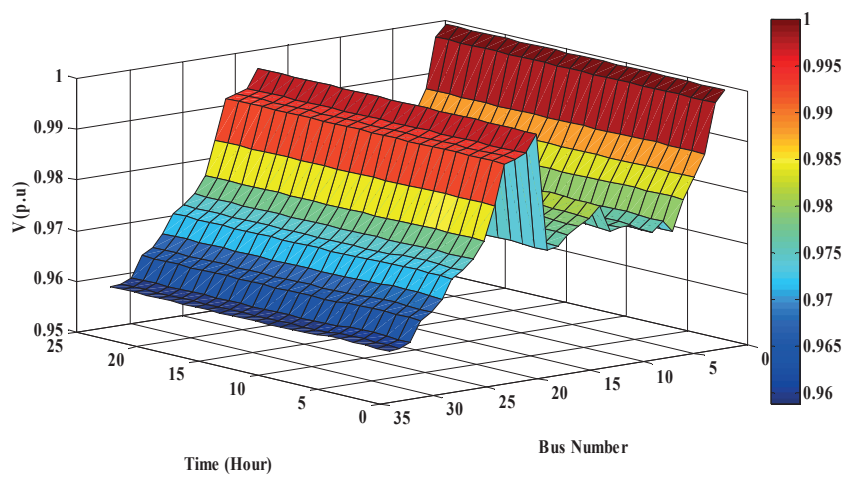

Fig.13. Expected voltage profile of 33 bus system with two SVC.

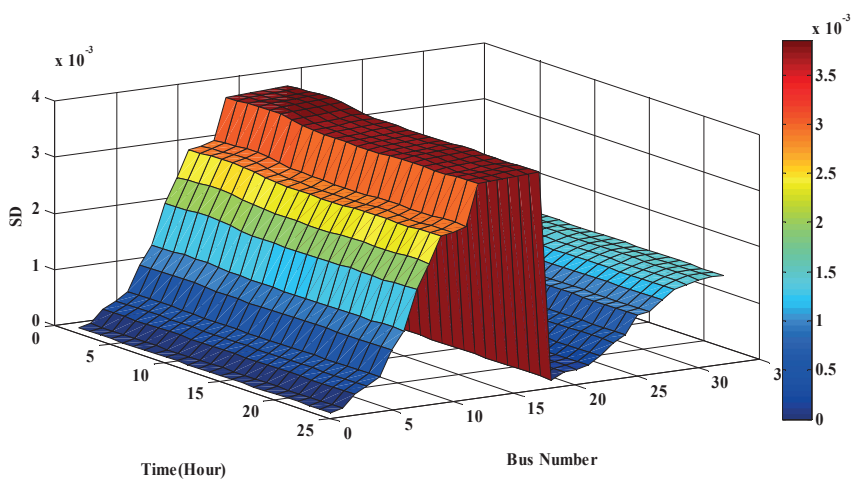

Fig. 14. Standard Deviation of 33 bus system with two SVC.

TABLE V. Stochastic Information of the System With/Without SVC FOR 33 BUS SYSTEM

\begin{tabular}{ccccccc}
\hline & \multicolumn{2}{c}{ Without SVC } & \multicolumn{2}{c}{ One SVC } & \multicolumn{2}{c}{ Two SVCs } \\
\cline { 2 - 7 } Mean & SD & Mean & SD & Mean & SD \\
\cline { 2 - 7 } Vmax & 0.9970 & 0.00005 & 0.9976 & 0.00004 & 0.9978 & 0.00004 \\
Vmin & 0.9131 & 0.00243 & 0.9307 & 0.00196 & 0.9588 & 0.00377 \\
Ploss (kW) & 202.67 & 0.00218 & 156.38 & 0.00205 & 184.57 & 0.00208 \\
Qloss (kVAR) & 135.14 & 0.00557 & 122.82 & 0.00457 & 112.12 & 0.00550 \\
VD & 0.0869 & 0.00025 & 0.0653 & 0.00023 & 0.0367 & 0.00019 \\
\hline \hline
\end{tabular}

TABLE VI. COMPUTATION Times

\begin{tabular}{ccc}
\hline & Analytical technique (s) & MCS (s) \\
\hline Without SVC & 15.0 & 1611.8 \\
With one SVC & 69.08 & 10516 \\
With two SVCs & 73.93 & 11978 \\
\hline
\end{tabular}

\section{B. 69-Bus Test System}

The proposed approach is also tested on 69-bus radial distribution system shown in Fig. 15 [34]. CDF of the voltage at bus 27 and bus 65 without SVC are shown in Fig. 16. Table VII and Table VIII show the values of optimal location and size of SVC in 69-bus system with different multi-objective optimization algorithms. From these tables the PESA-II still gives the better solution as in the previous test system. Fig. 17 gives PDF and CDF of voltages at bus 27 bus with and without SVC. Fig. 18 shows PDF and CDF of voltages at bus 65. Fig. 19 shows voltage profile of 69 bus in different cases. Pareto Optimal Front for 69 bus is shown in Fig. 20 and Fig. 21. Expected voltage profile of 33 bus system with single SVC in 24 hours is shown in Fig. 22; however, Fig. 23 gives the SD of it in 24 hours. Expected voltage profile of 69 bus system with two SVC in 24 hours is shown in Fig. 24, however, Fig. 25 gives the SD of it in 24 hours.

Table IX gives a comparison between expected and SD values with/ without SVC, the expected value of $\mathrm{V}_{\min }$ and $\mathrm{V}_{\max }$ are improved in both cases also $\mathrm{Q}_{\text {losses }}$ is decreased in case 2 than case 1 , however, the standard deviation is not improved in two cases compared to without $\mathrm{SVC}$. Table $\mathrm{X}$ gives computation time of two cases.

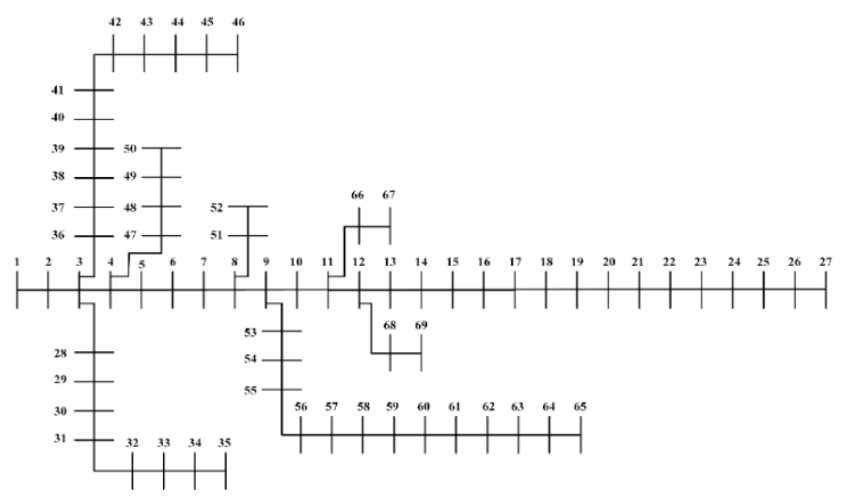

Fig. 15. 69 bus single line diagram.

TABLE VII. Optimal Size and Location of Single SVC Using Different OptimizATION Algorithms For 69 Bus System

\begin{tabular}{ccccc}
\hline \hline Method & $\begin{array}{c}\text { SVC } \\
\text { Location }\end{array}$ & $\begin{array}{c}\text { SVC Size } \\
(\mathrm{kVAR})\end{array}$ & $\begin{array}{c}\text { Power losses } \\
(\mathrm{kW})\end{array}$ & VD (p.u) \\
\hline MOPSO & 63 & 3055.60 & 278.17 & 0.0444 \\
NSGA II & 63 & 2306.92 & 196.64 & 0.0541 \\
PESA-II & 60 & 2245.33 & $\mathbf{1 8 4 . 1 1}$ & $\mathbf{0 . 0 6 0 3}$ \\
SPEA2 & 62 & 2370.93 & 196.80 & 0.0542 \\
\hline \hline
\end{tabular}

TABLE VIII. Optimal Size and Location of Two SVC Using Different OptimizATION AlgORIthMS FOR 69 Bus System

\begin{tabular}{ccccc}
\hline Method & $\begin{array}{c}\text { SVC } \\
\text { Location }\end{array}$ & $\begin{array}{c}\text { SVC Size } \\
(\mathrm{kVAR})\end{array}$ & $\begin{array}{c}\text { Power losses } \\
(\mathrm{kW})\end{array}$ & $\begin{array}{c}\text { VD } \\
(\mathrm{p} . \mathrm{u})\end{array}$ \\
\hline \multirow{2}{*}{ MOPSO } & 55 & 2567.40 & 302.69 & 0.0398 \\
& 63 & 2387.40 & & \\
NSGA II & 56 & 1627.94 & 297.87 & 0.0397 \\
& 63 & 2651.04 & & \\
PESA-II & 56 & 1394.32 & $\mathbf{2 6 5 . 4 0}$ & $\mathbf{0 . 0 4 2 9}$ \\
& 63 & 2508.19 & & \\
SPEA2 & 56 & 1791.39 & 298.17 & 0.0397 \\
\hline
\end{tabular}




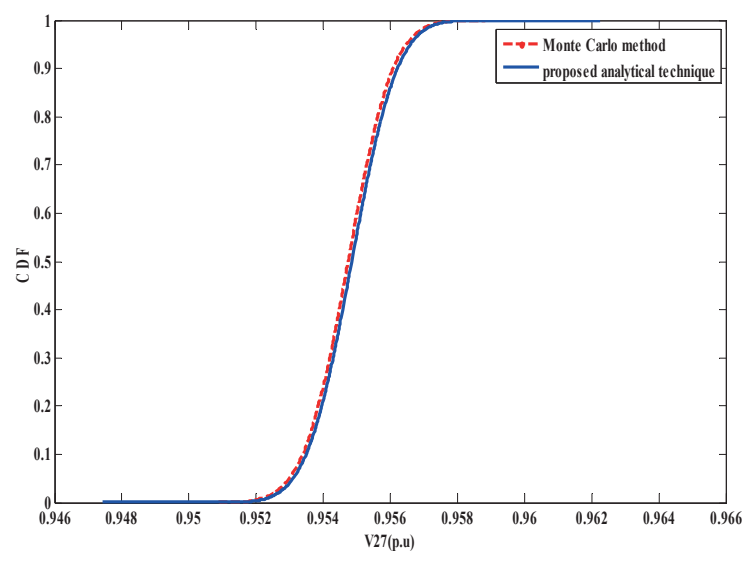

a. CDF of voltage at bus 27.

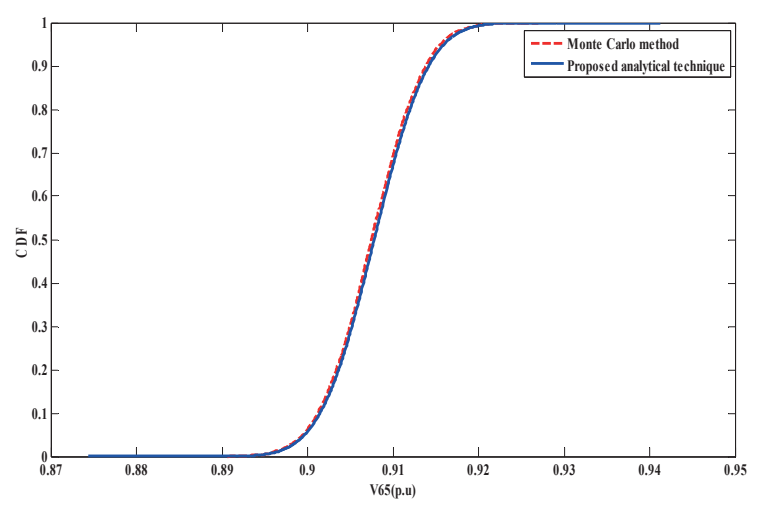

b. CDF of voltage at bus 65 .

Fig. 16. CDF of voltage at bus 27 and bus 65 without SVC.

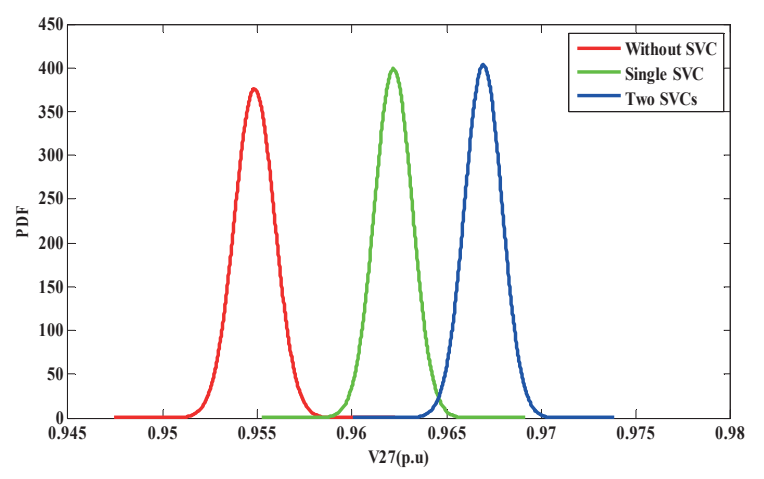

a. PDF

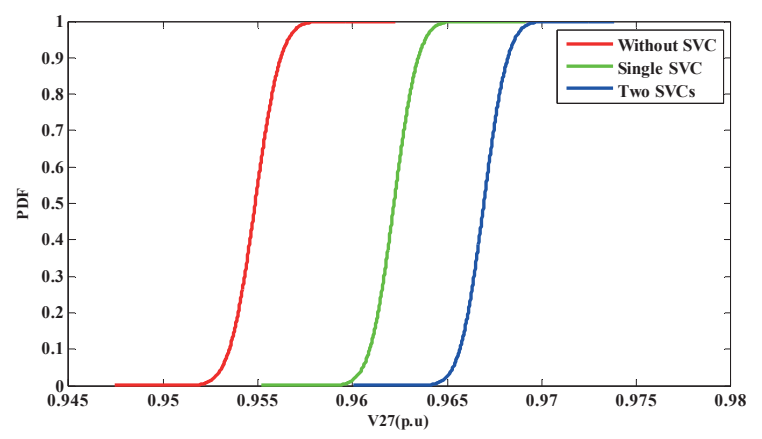

b. $\mathrm{CDF}$

Fig. 17. PDF and CDF of without/with implementation SVC at bus 27.

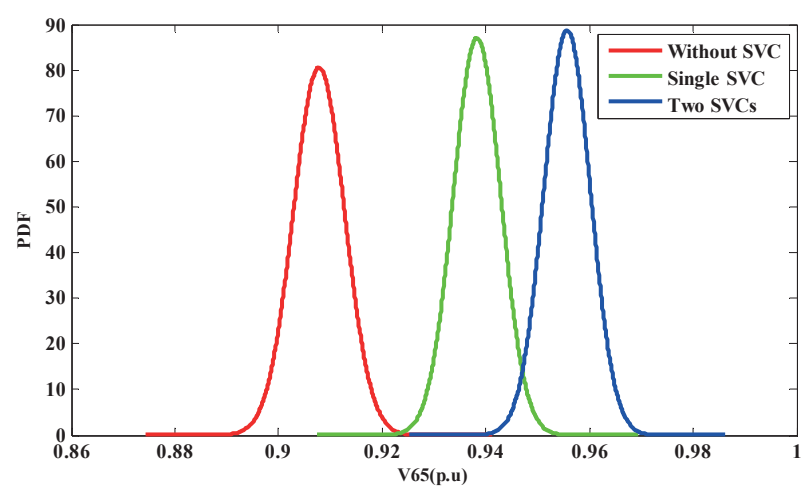

a. PDF

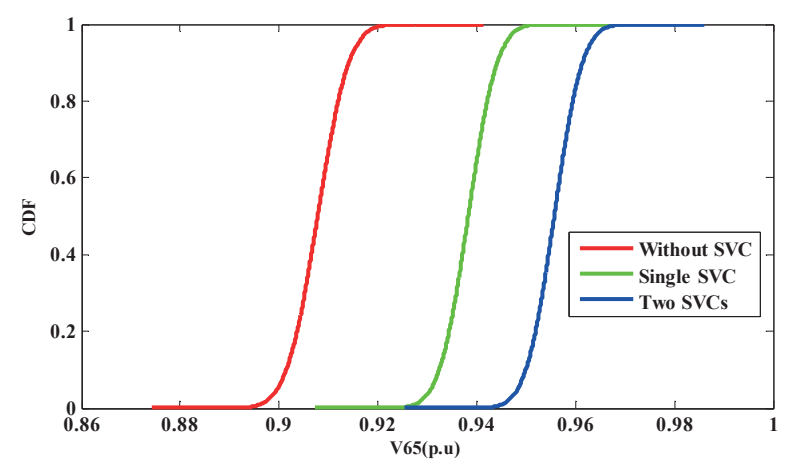

b. $\mathrm{CDF}$

Fig. 18. PDF and CDF of without/with implementation SVC at bus 65 .

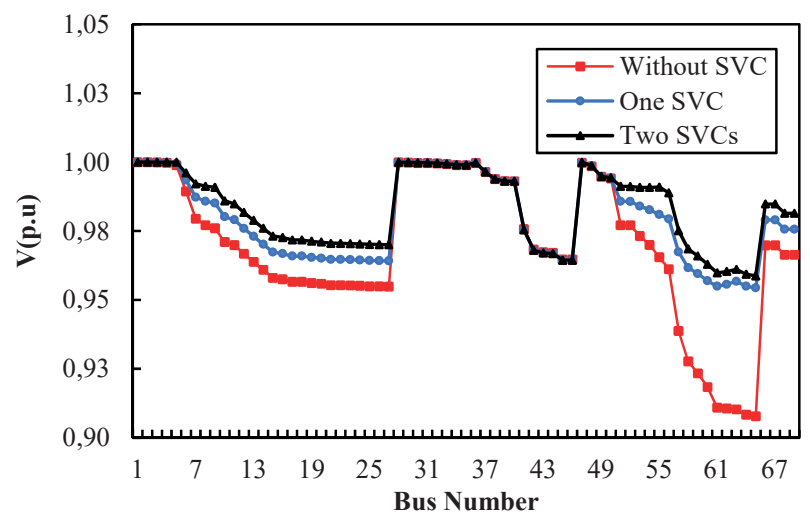

Fig. 19. Voltage profile of 69 bus with control device in different cases.

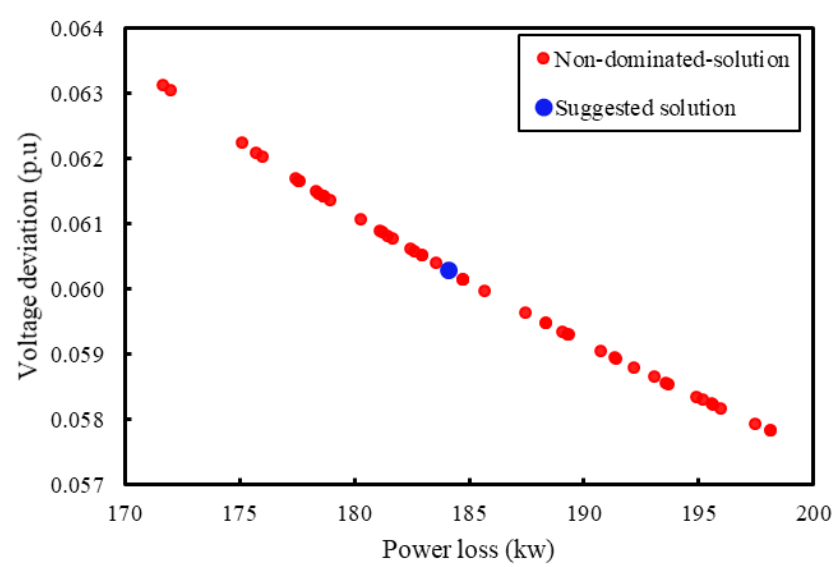

Fig. 20. Pareto Optimal Front for 69 bus with single SVC. 


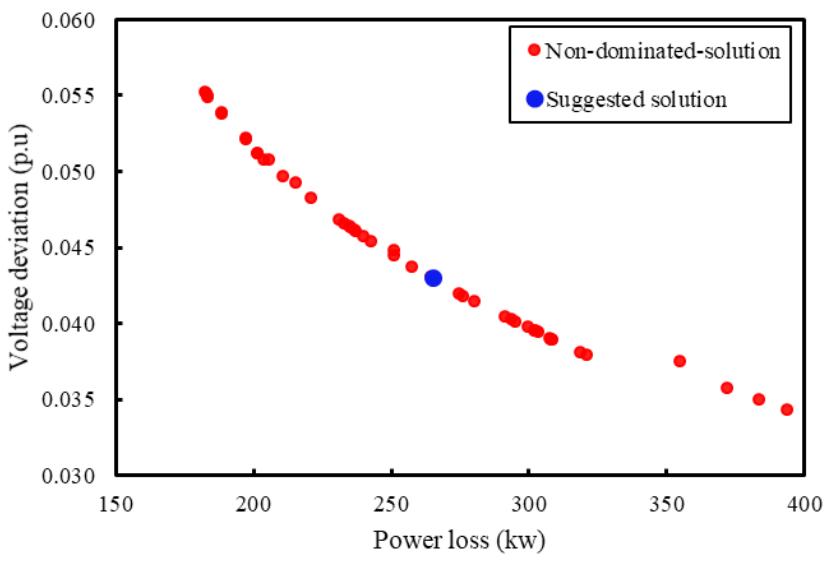

Fig. 21. Pareto Optimal Front for 69 bus with two SVC.

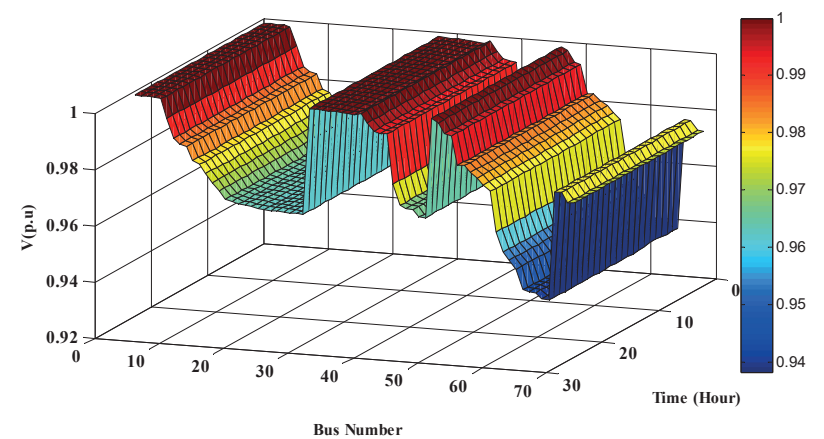

Fig. 22. Expected voltage profile of 69 bus system with single SVC.

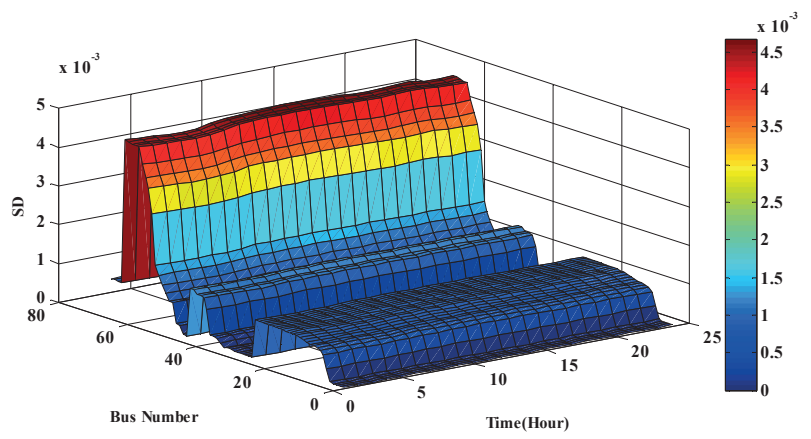

Fig. 23. Standard Deviation of 69 bus system with single SVC.

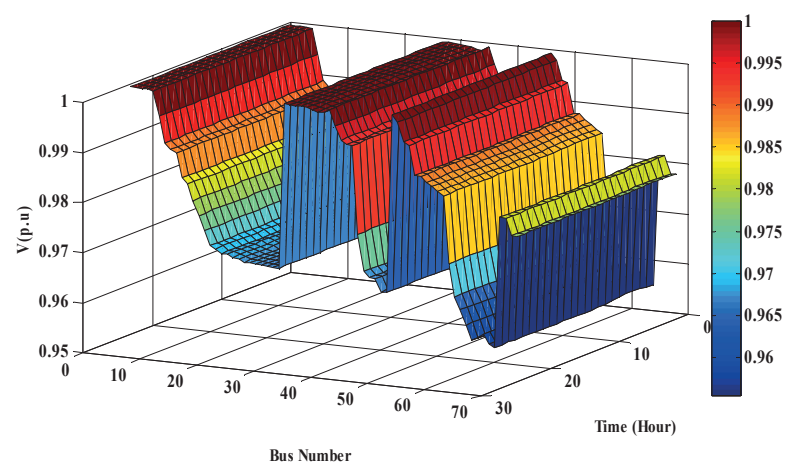

Fig. 24. Expected voltage profile of 69 bus system with two SVC.

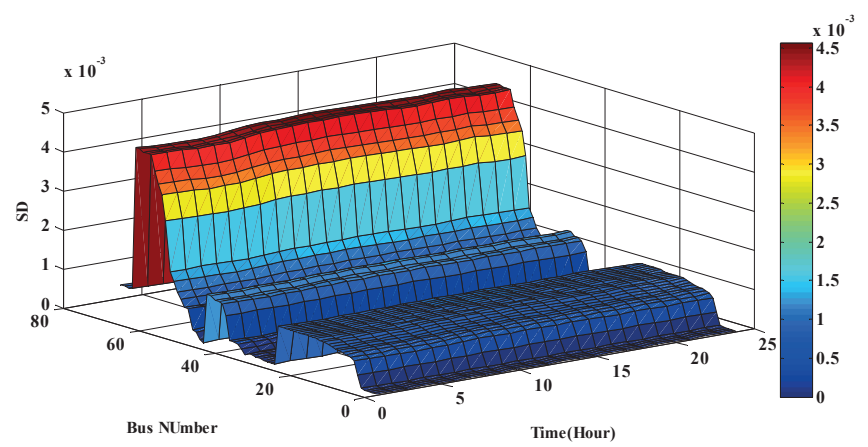

Fig. 25. Standard Deviation of 69 bus system with two SVC.

TABLE IX. Stochastic Information of the System With/Without SVC FOR 69 BUS SYSTEM

\begin{tabular}{ccccccc}
\hline & \multicolumn{2}{c}{ Without SVC } & \multicolumn{2}{c}{ One SVC } & \multicolumn{2}{c}{ Two SVCs } \\
\cline { 2 - 7 } Vmax & Mean & SD & Mean & SD & Mean & SD \\
\cline { 2 - 7 } Vmin & 0.9999 & $1.13 \mathrm{E}-06$ & 0.9999 & $1.13 \mathrm{E}-06$ & 1.0001 & $1.12 \mathrm{E}-06$ \\
Ploss (kW) & 0.9092 & 0.00124 & 0.9622 & 0.00109 & 0.9557 & 0.0045 \\
Qloss (kVAR) & 102.145 & 0.008723 & 184.11 & 0.007723 & 265.40 & 0.007686 \\
VD & 0.0908 & 0.00123 & 0.0603 & 0.000988 & 0.0429 & 0.00458 \\
\hline
\end{tabular}

TABLE X. COMputation Times

\begin{tabular}{ccc}
\hline & Analytical technique (s) & MCS (s) \\
\hline Without SVC & 32.012 & 3611.8 \\
With one SVC & 80.57 & 12709 \\
With two SVCs & 85.23 & 12845 \\
\hline \hline
\end{tabular}

\section{Conclusion}

In this paper, the probabilistic load flow problem considering the optimal location and size of SVC in radial distribution system has been solved. Pareto Envelope-based Selection Algorithm II (PESA-II) has been utilized to achieve the target of this paper and minimize the total power loss and voltage deviation based on the optimal location and size of SVC. Combined cumulants and gram-chalier expansion have been used for solving probabilistic load flow problem. The proposed methodology has been validated using the standard 33- bus and 69-bus distribution systems. The results give an acceptable solution with a low number of iterations and less computation cost compared to the Monte Carlo method (MCS).

\section{REFERENCES}

[1] M. Rahmani-andebili, "Reliability and economic-driven switchable capacitor placement in distribution network," IET Generation, Transmission \& Distribution, vol. 9, pp. 1572-1579, 2015.

[2] E. Shahryari, H. Shayeghi, and M. Moradzadeh, "Probabilistic and Multi-Objective Placement of D-STATCOM in Distribution Systems Considering Load Uncertainty," Electric Power Components and Systems, vol. 46, pp. 27-42, 2018.

[3] A. Selim, M. Abdel-Akher, M. M. Aly, S. Kamel, and T. Senjyu, "Fast quasi-static time-series analysis and reactive power control of unbalanced distribution systems," International Transactions on Electrical Energy Systems, vol. 0, p. e2673, 2018.

[4] M. M. Farsangi, H. Nezamabadi-pour, Y.-H. Song, and K. Y. Lee, "Placement of SVCs and selection of stabilizing signals in power systems," IEEE Transactions on Power Systems, vol. 22, pp. 1061-1071, 2007.

[5] M. Saravanan, S. M. R. Slochanal, P. Venkatesh, and J. P. S. Abraham, "Application of particle swarm optimization technique for optimal location of FACTS devices considering cost of installation and system loadability," Electric Power Systems Research, vol. 77, pp. 276-283, 2007. 
[6] S. Kamel, F. Jurado, and D. Vera, "A simple implementation of power mismatch STATCOM model into current injection Newton-Raphson power-flow method," Electrical Engineering, vol. 96, pp. 135-144, 2014.

[7] M. Abdel-Nasser, K. Mahmoud, and H. Kashef, "A Novel Smart Grid State Estimation Method Based on Neural Networks," International Journal of Interactive Multimedia and Artificial Intelligence, vol. 5, 2018.

[8] K. Mahmoud and M. Abdel-Nasser, "Fast-yet-Accurate Energy Loss Assessment Approach for Analyzing/Sizing PV in Distribution Systems using Machine Learning," IEEE Transactions on Sustainable Energy, 2018.

[9] A.G.Azar, M.Afsharchi, M.Davoodi, and B.S. Bigham, "A multiobjective market-driven framework for power matching in the smart grid," Engineering Applications of Artificial Intelligence, 70, pp.199-215, 2018.

[10] E. Dall'Anese, and A. Simonetto, "Optimal power flow pursuit," IEEE Transactions on Smart Grid, 9(2), pp.942-952, 2018.

[11] T. Yang and Y. Yu, "Steady-state Security Region-based Voltage/Var Optimization Considering Power Injection Uncertainties in Distribution Grids," IEEE Transactions on Smart Grid, 2018.

[12] R. Benabid, M. Boudour, and M. Abido, "Optimal location and setting of SVC and TCSC devices using non-dominated sorting particle swarm optimization," Electric Power Systems Research, vol. 79, pp. 1668-1677, 2009.

[13] G. Kour, G. Brar, and J. Dhiman, "Improvement by voltage profile by static Var compensators in distribution substation," International Journal of Instrumentation Science, vol. 1, pp. 21-24, 2012.

[14] J. D. Knowles and D. W. Corne, "Approximating the nondominated front using the Pareto archived evolution strategy," Evolutionary computation, vol. 8, pp. 149-172, 2000.

[15] K. Deb, A. Pratap, S. Agarwal, and T. Meyarivan, "A fast and elitist multiobjective genetic algorithm: NSGA-II," IEEE transactions on evolutionary computation, vol. 6, pp. 182-197, 2002.

[16] E. Zitzler, M. Laumanns, and L. Thiele, "SPEA2: Improving the strength Pareto evolutionary algorithm," TIK-report, vol. 103, 2001.

[17] C. A. C. Coello, G. T. Pulido, and M. S. Lechuga, "Handling multiple objectives with particle swarm optimization," IEEE Transactions on evolutionary computation, vol. 8, pp. 256-279, 2004.

[18] D. W. Corne, J. D. Knowles, and M. J. Oates, "The Pareto envelope-based selection algorithm for multiobjective optimization," in International conference on parallel problem solving from nature, 2000, pp. 839-848.

[19] G. T. Temur, "A novel multi attribute decision making approach for location decision under high uncertainty," Applied Soft Computing, vol. 40, pp. 674-682, 2016

[20] F. Ruiz-Rodriguez, J. Hernandez, and F. Jurado, "Probabilistic load flow for photovoltaic distributed generation using the Cornish-Fisher expansion," Electric Power Systems Research, vol. 89, pp. 129-138, 2012.

[21] X.-F. Wang, Y. Song, and M. Irving, Modern power systems analysis: Springer Science \& Business Media, 2010.

[22] B. Borkowska, "Probabilistic load flow," IEEE Transactions on Power Apparatus and Systems, pp. 752-759, 1974.

[23] B. B. a. C. H. G. R. N. Allan, "Probabilistic analysis of power flows," Proceedings of the Institution of Electrical Engineers (London), vol. 121, p. 12, Dec. 1974

[24] R. Allan and A. L. Da Silva, "Probabilistic load flow using multilinearisations," in IEE Proceedings C (Generation, Transmission and Distribution), 1981, pp. 280-287.

[25] A. L. Da Silva, R. Allan, S. Soares, and V. Arienti, "Probabilistic load flow considering network outages," in IEE Proceedings C (Generation, Transmission and Distribution), 1985, pp. 139-145.

[26] F. Ruiz-Rodriguez, J. Hernandez, and F. Jurado, "Probabilistic load flow for radial distribution networks with photovoltaic generators," IET renewable power generation, vol. 6, pp. 110-121, 2012.

[27] F. Ruiz-Rodriguez, M. Gomez-Gonzalez, and F. Jurado, "Reliability optimization of an electric power system by biomass fuelled gas engine," International Journal of Electrical Power \& Energy Systems, vol. 61, pp. 81-89, 2014.

[28] G. J. Anders, Probability Concepts in Electric Power Systems New York: Wiley, January 1990.

[29] P. Amid, and C.Crawford, "A Cumulant-Tensor Based Probabilistic Load Flow Method," IEEE Transactions on Power Systems, 2018.

[30] W. Li, Probabilistic transmission system planning vol. 65: John Wiley \&
Sons, 2011.

[31] P. Zhang and S. T. Lee, "Probabilistic load flow computation using the method of combined cumulants and Gram-Charlier expansion," IEEE transactions on power systems, vol. 19, pp. 676-682, 2004.

[32] J. M. Morales and J. Perez-Ruiz, "Point estimate schemes to solve the probabilistic power flow," IEEE Transactions on Power Systems, vol. 22, pp. 1594-1601, 2007.

[33] J. Liu, M. Salama, and R. Mansour, "An efficient power flow algorithm for distribution systems with polynomial load," International Journal of Electrical Engineering Education, vol. 39, pp. 371-386, 2002.

[34] M. Baran and F. F. Wu, "Optimal sizing of capacitors placed on a radial distribution system," IEEE Transactions on power Delivery, vol. 4, pp. 735-743, 1989.

\section{Walaa Ahmed}

Walaa Ahmed received the B.Eng. from the Faculty of Engineering, South Valley University, Egypt in 2015. She is currently pursuing his MSc degree in Department of Electrical Engineering, Aswan Faculty of Engineering, Aswan University. Her research activities include power system modeling, analysis, and optimization

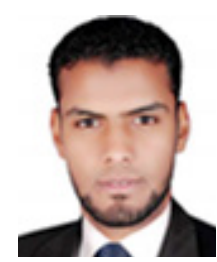

Ali Selim

Ali Selim received his BSc and MSc degrees in Electrical Engineering from Aswan University, Egypt, in 2010 and 2016 respectively. He is currently a Ph.D. student in the Department of Electrical Engineering at University of Jaén (Universidad de Jaén), Spain. His research interests include mathematical optimization, planning and control of power systems, renewable energies, energy storage, and smart grids.

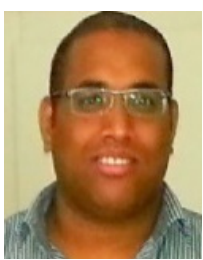

\section{Salah Kamel}

Salah Kamel received the international Ph.D. degree from University of Jaen, Spain (Main) and Aalborg University, Denmark (Host) in Jan. 2014. He is an Assistant Professor in the Electrical Engineering Department, Aswan University. Also, He is a Leader for a power systems research group in the Advanced Power Systems Research Laboratory (APSR Lab), Aswan, Egypt. He is currently a Senior Research Fellow in State Key Laboratory of Power Transmission Equipment and System Security and New Technology, School of Electrical Engineering, Chongqing University, Chongqing, China. His research activities include power system modeling, analysis and simulation, and applications of power electronics to power systems and power quality.

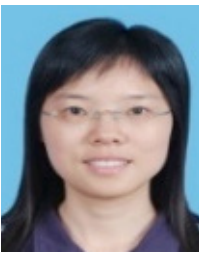

Juan Yu

Juan Yu received the Ph.D. degree in electrical engineering in 2007 from Chongqing University, Chongqing, China, where she is currently a Full Professor. Her research interests include static equivalent, optimal reactive power flow, and risk assessment in power and energy systems.

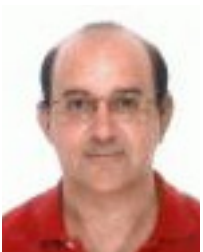

\section{Francisco Jurado}

Francisco Jurado obtained the MSc and $\mathrm{PhD}$ degrees from the UNED, Madrid, Spain, in 1995 and 1999 respectively. He is Full Professor at the Department of Electrical Engineering of the University of Jaén, Spain. His research activities have focused on two topics: power systems and renewable energy. 